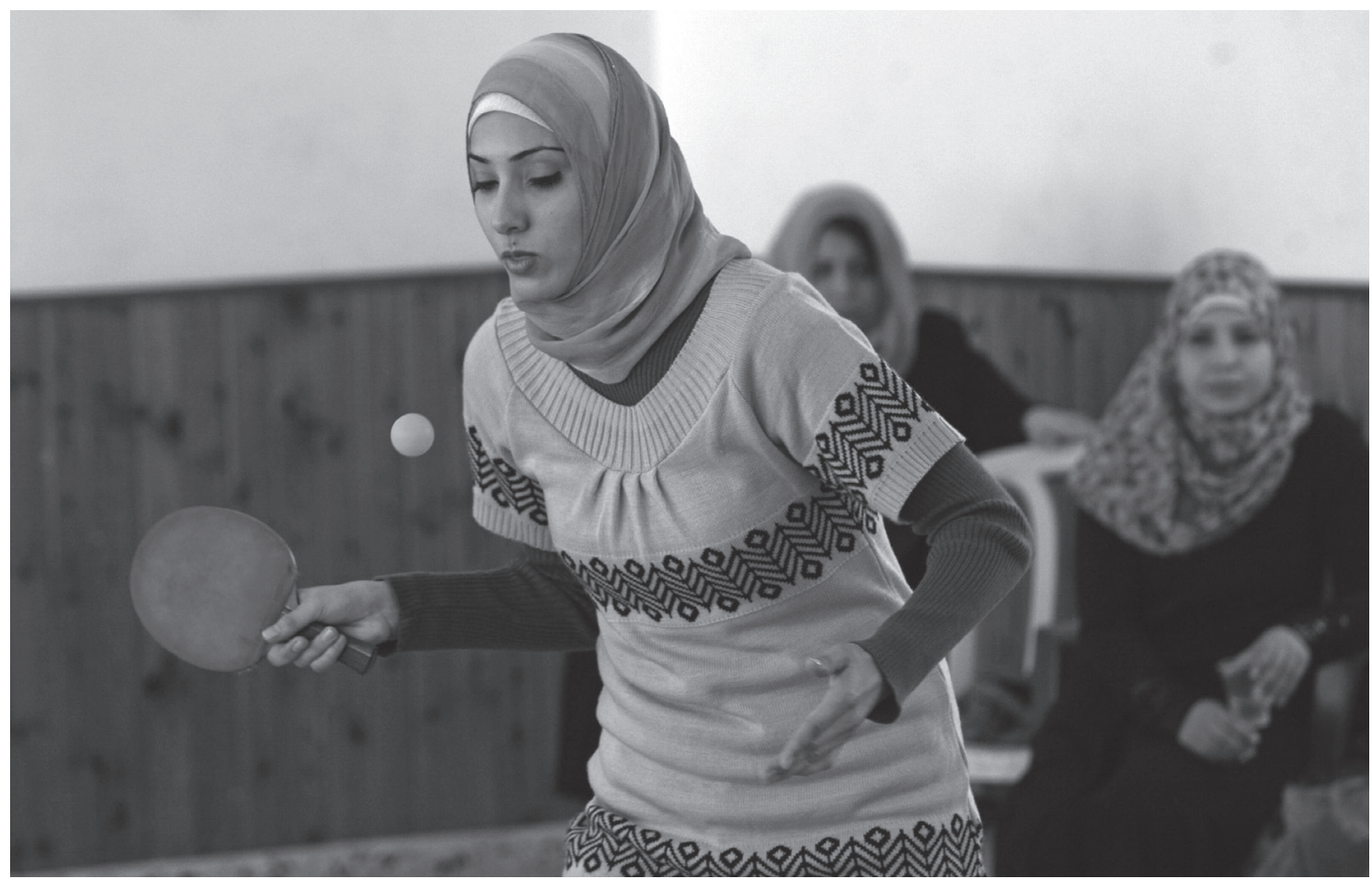

A Palestinian Muslim Woman plays table tennis in a rare competition among women in the Hamas-rum Gaza Strip, December 2009 (Photo: Mahmud Hams/Scanpix).

\title{
Women and Sport in Islamic Countries
}


Modern sports claim to guarantee equality and especially the equal right to compete in them. The Olympic Charter, and more particularly the "Codification of the Fundamental Principles of Olympism" states that "every discrimination with regard to a country or a person on grounds of race, religion, politics, ... is incompatible with ... belonging to the Olympic Movement". ${ }^{1}$ The 'Sports for all' movement similarly aims at inclusiveness and participation by all, men and women alike. Both movements are rooted in Western cultures, and it is the intent of this paper to explore if and how Western sports discourses and practices can contribute to women's development in Islamic countries. ${ }^{2}$

This article focuses on sports and physical activities of girls and women in Islamic countries. It will inform the readers about opportunities and barriers that these women's faces in elite sports (especially in the Olympic Games), as well as at the 'Sports for all' level. Special focus will be placed on the reasons for their (lack of) engagement in sports. In addition, the article will discuss initiatives aiming at stimulating sport participation by Muslim women

\section{ELITE SPORTS AND WOMEN FROM ISLAMIC COUNTRIES}

\section{Olympic Games}

Participation by women in the Olympic Games mirrors the development of women's sports in general. In 1896, women were excluded from the Games, but their participation rate grew slowly and steadily from the time the Olympics were held in Paris, France (1900). In 1908 the percentage of female athletes was $2 \%,{ }^{3} 8 \%$ in 1938, $11 \%$ in 1960, and in 2008 (Beijing) more than $42 \%$ of the athletes were women who par- ticipated in 26 of the 28 sports and in 137 of the 302 events. $^{4}$

The gradual increase in the number of female Olympians clouds the reality that a woman's opportunity to participate and compete in sports, and in the Olympic Games in particular, depends to a large extent on her cultural and religious background. Traditionally, Islamic cultures do not prioritise "modern sport" and thus the number of athletes from Islamic countries who compete in the Olympic Games continues to be quite low. In 2008, 427 men (6\% of male athletes) and 98 women ( $2 \%$ of female athletes) from Islamic countries ${ }^{6}$ competed in the Olympic Games. This is a small number in the view of the fact that around $20 \%$ of the world population adheres to Islam. Up to the 1980 s, only women from "secularised" countries, i.e. Turkey and pre-revolutionary Iran, had the opportunity to compete in the Olympics. The first female Olympians from an Islamic country were two fencers from Turkey, who participated in the Olympic Games in $1936 .^{7}$ Iranian female track and field athletes and gymnasts competed in the Olympic Games in Tokyo in 1964. In 1968 and 1972, the Iranian National Olympic Committee (NOC) did not send women to the Olympic Games, but in 1976, female athletes from Iran participated in fencing competitions. Three Egyptian women qualified for the Olympic Games in 1960 but for unclear reasons they did not participate. However, the Egyptian NOC was amongst the first Islamic NOCs to send women to the Olympics. In 1984, five female athletes represented Egypt in diving, swimming and synchronized swimming. The swimmers owed their Olympic participation to Safeya (Sofi) Tharwat a former athlete and powerful woman in the Egyptian Swimming Federation (Alsharif, 2008). ${ }^{8}$ 
The success of the first generation of female Olympians from Islamic countries was based on their representation at the Games rather than on their results. Only with the participation of North-African athletes in the Olympics of the 1980s, women from Islamic countries took part in the challenge for medals. In 1984, the Moroccan, Nawal El Moutawakel, a 400m hurdler, won a gold medal as the first woman from an Islamic country. In the 1992 Olympic Games, the Algerian native, Hassiba Boulmerka, became the gold medal winner in the $1500 \mathrm{~m}$ race. She ran in shorts causing such an uproar among religious fundamentalists that she had to leave her country.

With regard to the inclusion of women in the national Olympic delegations of Islamic countries, progress has occurred over the past decades. More specifically, of the 160 NOCs involved in the Seoul Olympics (1988), 42 (including 21 Islamic country NOCs) sent only male athletes (Hargreaves, 1997, p. 227). 33 NOCs did not include women on their teams to the Barcelona Olympics (1992), 28 NOCs to the Atlanta Olympics (1996), and 9 NOCs to the Sydney Olympics (2000). Only three delegations (Saudi Arabia, Qatar and Kuwait) had "men only" teams in 2008 at the Beijing Games. Jordan's delegation consisted of three men and four women and the North African nations included a considerable number of female athletes, even a women's volleyball team (Bannayan, 2008). Oman and the United Arab Emirates, for the first time, sent women to Olympic Games.

A view of the medal count at the Olympics in 2008 shows that only a few delegations (nations) shared the medals: 15 of the more than 100 teams won $75 \%$ of the gold medals. The successful teams, with few exceptions, came from Western industrialized countries and from China. ${ }^{9}$

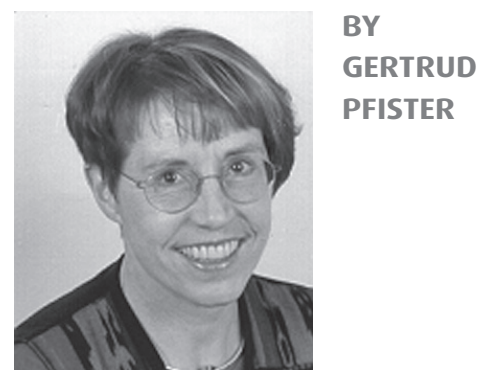

Turkey was the most successful Islamic country at the 2008 Olympics having won 8 medals, four of which were won by 20 female athletes. Two silver medals in the $10,000 \mathrm{~m}$ and $5,000 \mathrm{~m}$ races were won by Elvan Abeylegesse, the female long distance runner of Ethiopian origin. Sibel Ozkan won a silver medal in weightlifting, a sport with a Turkish tradition (note that in 2004, the weightlifter Nurcan Taylan had become the first Turkish female athlete to win a gold medal). In 2008, another silver medal was won by Azize Tanrikulu in taekwondo. 20 female athletes and 48 male athletes competed in the 2008 Beijing Olympics. In addition, there were two further female medal winners from Islamic countries, an Algerian judoka and a Moroccan $800 \mathrm{~m}$ runner.

The low level of participation and low success rate ( 6 medals out of 958 medals were won by women from Islamic countries) clearly points to the marginalization of this group in the Olympic Games, which is still a serious problem, but remains an under-researched and disregarded issue. $^{10}$

Many female Olympians from Islamic countries do not meet the required performance standards but compete in the Games because in some sports the countries are allowed to send at least one competitor. In other sports they are granted "wild cards". With a few exceptions, 
these women have no opportunity to reach even the second round of the competitions. They do not fail because they are less talented, have less will power or engagement but because they have to struggle with constraints from the lack of training facilities and financial support to conflicts with families or attacks from Islamists. Although women's participation in the Olympics is a contested issue among traditional Muslims, women from Islamic countries are extremely proud to represent their nations and their compatriots join their female athletes in the celebration of national and Muslim identity.

\section{Competitive sports}

Despite the numerous barriers that exist, women in Islamic countries have managed to become successful athletes, even in martial arts like karate or taekwondo. This is especially true in the case of Turkey where the separation of State and religion and the westernization of the middle classes in large cities provide a positive climate for women's sports (Pfister, 1997). According to Koca and Hacisoftaoglu (2010) who draw on information from the Turkish Government Agency for Sports, the number of female athletes has increased threefold since 1997. ${ }^{11}$

Currently, $13 \%$ of the 420,000 elite athletes in Turkey are women. Most of the 57,000 sports women in the 23 million female population (1564 years of age) compete in volleyball (approx. 1,100 women), taekwondo (9,000), basketball $(5,000)$, karate $(4,000)$, and 2,000 or less in swimming, kickboxing, handball and judo.

One example of women overcoming barriers in sports is that of the Turkish elite athlete, Hamide Bıkçın Tosun, a bronze medal winner in the 2000 Olympic Games and a mother, who covers her hair in daily life and, to the extent possible, also during taekwondo competitions. An- other example is that of the Syrian female athletes who compete in national and even international competitions, mostly in Pan-Arabian, Asian or Mediterranean tournaments and championships. Successful female athletes, as the Syrian Ghada Shouaa a track and field athlete, winner of the heptathlon in the 1996 Games, are treated as heroines (El Houda Karfoul, 2010). The same is true for Malaysian athletes (Wirdati, 2006) and sports women from many other Islamic countries.

These success stories should not hide the fact that women in Islamic countries are a small minority in the competitive sports arena. They remain marginalised when compared with male athletes and are often stereotyped as unfeminine and bad Muslims. They lack resources and facilities and face resistance based on religion, tradition and culture. Structural and economic problems impede sports development in many Islamic countries but women more than men are affected in many ways and to a much higher degree (Benn, Pfister \& Jawad, 2010).

It should be emphasised, however, that participation in sports, and especially in elite sports, is not a valued activity per se. On the contrary, sports face criticism in Western as well as in Islamic countries. Top level sport is flaunted through commercialisation, affected by an increasing sexualisation of the athletes, and endangered by legal and illegal performance enhancements. Not participation but winning at all cost seems to be the aim of the athletes.

\section{SPORTS FOR ALL}

Little is known about physical activities and 'Sports for all' in the case of girls and women in Islamic countries. A situation overview of women's sports and physical education in Bahrain, Syria, Turkey, Iran and Oman is provided in the 
book Muslim Women and Sport (Benn, Pfister \& Jawad, 2010). The information provided as well as other sources about Egypt and Kuwait, for example, indicate that in many of these countries 'a substructure of girls' and women's sports has been established, although there remain huge disparities in financing between sports for boys or girls; and sports for men or women" (Hargreaves, 2007, p. 82)

Al-Hadair states in his $\mathrm{PhD}$ dissertation (2004): “Throughout modern times, sport and other recreational forms of exercise have never been an organic feature of the cultural history of Muslim women"(here quoted in Hargreaves, 2007, 75). Schools and colleges may provide sports opportunities for female students (mostly gender segregated) (Hargreaves, 2007, Benn, Pfister \& Jawad, 2010). Some Islamic countries, e.g. Syria, Iran and Oman, have imported the club system from Europe. Here clubs organise sports and games but only a minority of club members and sports participants are girls and women.

In 2007, the 380 certified Sports Clubs in Syria had 206,164 members, 19,740 were women $(9,6 \%)$. This is a very small number compared with the 5.3 million women in the age group 1564 years. Sports practiced by girls and women in Syrian clubs include athletics, swimming, gymnastics, basketball, handball, volleyball, table tennis, tennis, karate, judo, cycling, shooting, equestrian sports, and more recently, football and boxing (El Houda Karfoul, 2010). A similar under-representation of girls and women in sports can be found in Iran, although there exists a "women's sports movement", promoted especially by Faezeh Hashemi, the daughter of former Iranian President Rafsanjani (Pfister, 2010).

A specific combination of tradition and modernity permeates culture and lifestyle in the
Sultanate of Oman, one of the Arabic Gulf States with a tribal organization and Islamic guiding principles. In the 1970 s, the Sultan initiated modernization nationwide which included a measure of women's rights. Sports have no tradition in Oman but are supported due to their potential benefits in political, educational and health related areas. A number of sport clubs emerged that cater specifically to men's football. Women's sports, however, still face considerable resistance. According to Benn and Al-Sinani (2010) "Almost the only physical activity that receives approbation is walking. ... Certainly class distinctions remain and the wealthy and working Omani women can afford to attend the new ladies gymnasiums springing up in the cities." The country reports in Muslim Women and Sport reveal that two types of physical activities, i.e. walking and training in fitness centers are widely approved and find an increasing number of adherents. However, the authors of the reports also emphasize that only the members of middle- and upper classes can afford the membership entrance fees to these commercial centers. In some countries or cities, community based fitness facilities have been established, e.g. the "Ladies Locals" in Ankara, Turkey, that also provide training opportunities for less affluent women (Koca \& Hacisoftaoglu 2010, Benn, Pfister \& Jawad, 2010).

These glimpses into women's sports in Islamic countries show similarities and differences depending on the heterogeneity of Islamic cultures and the various ways in which Muslim women deal with their religion. There are huge opportunity differences between, for example, women from Egypt (where women enjoy a measure of freedom, at least in the big cities) and Saudi Arabia (where women are not allowed to drive). In addition, class differences must also be consid- 
ered. Upper class women in all Islamic countries have opportunities to adopt active lifestyles they have access to exclusive fitness centres, private sport clubs and spas or they use hotel facilities. The majority of the female population has to adapt to various rationales and regimes of religion and culture and has to negotiate spaces and opportunities for physical activities. Women in rural areas may still live in traditional ways and have to contribute to the sustenance of their families through physical work.

According to Hargreaves (2007, p. 74), "The bodies of Muslim women in sport are experienced and mediated through different ideological interpretations of Islam, within the particular political arrangements of specific countries and in ways that are penetrated to various extents by patriarchal relations of power and control". As already stated in the introduction, we must consider that sports have their roots in Western cultures and that the globalized image of female elite athletes influence - positively and negatively - the notion of women's sports in Islamic countries.

\section{BACKGROUNDS AND RATIONALES}

Islam and women's sport - empowerment and restrictions

Participation in sports by girls and women from Islamic countries is influenced by religion in various complex and ambiguous ways while there seems not to be a general prohibition of sports in Islam, a rule that is also applicable to girls and women. ${ }^{12}$ Islamic sports scientists emphasize that health and fitness are important for men and women alike and should be sustained by sporting activities. They legitimize their point of view with various hadith (oral traditions about the words and deeds of the Prophet Mo- hammed) and emphasize that Mohammed advocated a healthy lifestyle, recommending physical activities such as running, horseback riding, swimming and archery. Leila Sfeir emphasizes: "Islamic religion in no way tries to depreciate, much less deny sport for women. On the contrary, it attributes great significance and function to physical strength and sport activities. Islam has a constant concern with one's body, cleanliness, purification and force, with segregation of the sexes. But certain religious elements, such as Islamic fatalism ... have been dominant factors in controlling general access to sport" (Sfeir, 1985, p. 300, Daiman, 1995). These arguments are supported by Islamic feminists, who continue to fight for the rights of girls and women to participate in sporting activities.

Sports feminists with a "faith based" approach, who operate within an Islamic framework, refer to the Koran as support for their demand of equal opportunity for girls and women in sports and society. In contrast to secular feminists, they believe that equal opportunity in sports is compatible with the traditional Islamic rules with respect to "modest clothes" and/or segregation of the genders. Secular (sport) feminists - an almost silent minority - demand a separation of state and religion; they opt for freedom of choice with respect to religion and lifestyle and demand that women be given the same access as men to all parts of society, including sports.

There is, however, a third view on women, sport, and religion. Islamic feminists deny that segregation based on gender and the necessity of wearing the veil, are requirements in the Koran. Some Muslim scholars argue that there are no religious rules which prohibit participation in sports and/or the wearing of Western style clothes while playing sports or in everyday life. 
However, in some countries and/or groups, women's participation in sports remains irreconcilable with Islamic values and traditional and the culturally rooted concept of femininity and the gender roles and relations that restrict women's actions to the home and family (Sfeir, 1985, p. 300, Daiman, 1995).

According to Safeya (Sofi) Tharwat, board member of the Egyptian Swimming Union, Egyptians have become more conservative in their attitudes since the 1950s. She reports that "sports like fencing and horseback riding are less criticized because the outfits do not reveal much of the woman's body, but diving and swimming cause challenges... So we fight for the girls' rights to swim" (Alsharif, 2008). Hargreaves $(2007$, p. 88$)$ concludes that the greatest barrier for participation in sports by women from Islamic countries is "the opposition that continues to face them from Islamist leaders who wield power in their local communities. All forms of participation attract critical religious commentary from conservative Muslim clerics ... They encourage feelings of guilt and sometimes fear in young Muslim sportswomen who are ignorant of alternative Qu'ranic definitions of womanhood." One of the numerous examples of problems that Muslim athletes face despite wearing "modest" sporting attire, is the case of the Afghani runner Mehbooba Andyar who was so terrified by threats from Muslim fundamentalists that she decided not to participate in the Beijing Olympic Games. According to newspaper reports, she sought asylum in Norway. ${ }^{13}$

\section{Gender roles and relations in Islam}

In the Islamic culture the relationship between the genders and the situation of women are regulated by the Sharia, a legal system based on religious rules. The Sharia focuses on the family and enforces gender differences and gender hierarchies. Despite the claim of a universal area of application, the Sharia is used in different ways in Islamic countries.

In Islamic societies, the family takes central focus. Age and sex determine one's social position in the family as well as in society at large. The hierarchical organisation of the family and the strict division of labour according to gender play an important role in the Islamic culture. The family as well as the community force its members to assume specific roles and duties, but in return promise support, protection and social status (Delaney, 1991). According to the Sharia, the husband is the head of the family and decides on all major issues. He is obliged to care for sustaining his wife/wives who, in return, is/are committed to obedience. The husband has the right and the duty to control and "protect" the family members, especially the women and girls whose modesty and - in Islamist contexts "covered" bodies signalise gender differences and hierarchies (Sfeir, 1985, Nakamura, 2002, Schirrmacher \& Spuler-Stegemann, 2006). Gender hierarchies and the social and cultural superiority of men are based on the concept of honour and the regulation of sexuality (Schiffauer, 1983, Khader, 2006). In Islam, sexual relations only have a place inside of marriage. Sexual relations of unmarried couples are strictly forbidden and can be severely punished (in case of adultery even by stoning). Female sexuality is controlled by gender segregation. Women should either not appear in public or they must dress in "decent" clothes that fully cover their bodies. But we have to consider that gender roles and rules are complex and contested and there are various translations of the Koran as well as interpretations and negotiations with Islamic laws and cultures. 
According to Islamic tradition, family respectability and honour of its male members depend on the moral integrity of the wives and the virginity of the daughters. Men must control the female family members, prevent any actions which might dishonour them and sanction transgressions. In traditional Muslim communities, the main strategy is to control the women and to prevent them from having contact with the other gender. In the case of girls, this would include forbidding activities that could damage the hymen (Khader, 2006).

Leisure time physical activities, and sports may impact the respectability of women and the honour of their families in many ways. Women's participation in sports leaves them uncontrolled by the family and/or sports could empower girls and women, weakening family influence. The family's reputation may also be endangered if its female members were allowed to engage in activities that are seen as unfeminine, against Islamic laws or harmful to the female body (Nakamura, 2002).

\section{Covering the body - the hijab Meanings and practices}

For women in Islamic countries, integrity means following Islamic rules about the body and its representation in public. In Western countries, covering of the body, in Arab 'hijab', is seen as a visible and highly contested sign of „otherness“, and a cause for discrimination. For traditional Muslims, women's covered bodies have become symbols of Islam. "Women's bodies are pivotal in the mix of religion, politics and culture ... are central in the construction of a diasporic, truly global 'Muslim society'" (Hargreaves, 2007, p. 76). However, "covering” has various forms and meanings in Islamic countries, depending on the religious affiliation, the environment, the cultu- re, and tradition. In many countries the hijab covers the entire body with the exception of the face and the hands.

Women have various and often intertwined reasons to dress according to Islamic rule. A woman can be forced to wear a veil but it can also stem from her own decision. For religious women, "modesty" is an embodied part of her identity and a sign of her obedience to God. Some women wear a veil as protection against the male gaze. To wear a veil can also be a fashion mode or a habit. Women also choose to cover their bodies, not for religious purposes but because to "unveil" could be interpreted as an action against Islam. Thus, the veil signalizes solidarity with Islamic traditions and resistance against Western politics (Hargreaves, 2007, p. 75). In recent years, a growing number of girls and women also in Western countries have started to (re-)discover religion, to re-interpret Islam and to use the veil as an instrument of individual identity politics.

Women who believe in Islam and follow its rules may decide not to cover their heads. Some muslim feminists even claim that neither the Koran nor the hadiths demand that women are "covered" (or excluded from public life). According to these women, the socially constructed gender roles and rules are to be attributed to a mixture of Islam and patriarchal traditions rather than to religion. ${ }^{14}$

\section{The hijab and sports}

The sports attire of Muslim women is especially contested. In countries where traditional Islamic beliefs prevail, e.g. Iran and Saudi Arabia, women must wear the hijab in public and when they participate in physical activities. In countries like Oman, where the hijab is not mandatory but part of a still strong tradition, Omani 
women prefer (for various reasons) to wear traditional clothing when they are physically active in a mixed gender environment. However, "modest" dress does not necessarily restrict the activity range. Iranian women, for example, run, hike, ski, bike, and even play soccer in the "proper attire". Many Muslim women, however, prefer to participate in physical activities in women-only facilities not least because this allows them to wear sports clothes and be untroubled by the men.

Sports attire is also one of the main issues constraining participation by women from Islamic countries in the Olympics. The official dress codes in competitive sport do not conform to Islamic standards of modesty but most Muslim athletes opt to follow this code, claiming that does not conflict with their faith. This was/is also the conviction of Hassiba Boulmerka, gold medal winner in the Olympics in 1992. "Boulmerka is a symbol of resistance and progress of the Qur'an, and reflects the potential for Muslim women to develop their interests in the modern world without rejecting their Muslim faith" (Hargreaves, 2007, p. 83). However, dress codes that require a bathing suit or a bikini (as in beach volleyball) do not only conflict with the rules of many Islamic countries, but may also offend sensibilities of practicing Muslims. In some sports it is possible to cover the body and hair. Thus, the Bahraini Roqaya Al-Gassra, a $100 \mathrm{~m}$ and $200 \mathrm{~m}$ runner, competed in the Olympic Games in Athens and Beijing in long trousers, a shirt with long sleeves and a scarf. She and several other athletes affirmed via their attire their Islamic identity and gained approval and praise from traditional Islamic groups (Hargreaves, 2007 , p. 87). It can be discussed if these practices contradict the principles of modern sport which calls for equal access and rules. But one could argue that the aim of these principles is to guarantee fair conditions and that clothes that disadvantage the wearer do not affect the performance of the other athletes and the fairness of the competition. Sports equipment manufacturers are currently developing new types of clothes, among them body suits for swimming that could allow religious Muslim women to compete in previously "forbidden" events.

\section{Physical activities of girls and women from Islamic countries - structural and economic barriers}

Not only are religious and cultural restrictions barriers for women from Islamic countries, but living conditions, legal prohibitions and discriminations may prevent them - with few exceptions - from participating in sports, and more particularly in international sport competitions (Pfister, 1997, Pfister, 2003).

Alsharif (2008) reports, for example, about the situation of sports women in Egypt, a country that allows Western clothes and lifestyles: "But while there's been some record breaking, women in this country continue to face challenges above and beyond the race to the finish line. They report unequal treatment and fewer privileges within sports federations, and face a nation that has long held a less than positive perception of their involvement in sport ...."

In many countries, women's sports meet confrontation due to numerous concrete difficulties ranging from the absence of girls' physical education and the limited opportunities of practicing and training to the lack of competition. The female soccer players in Palestine, for example, have only very limited access to the only grass field available and thus face huge difficulties to train for international meetings. In addition to the lack of sport facilities, difficulties travelling 
due to political conflicts with Israel make proper training impossible (Kremers, 2010).

Even in countries with ample resources and an aspiration of modernization, girls and women face major difficulties at the regional and local levels. Al-Sinani \& Benn (2010) characterize the situation in Oman as follows: "Main challenges remain in working with communities to educate men and women about the values of physical activity. Also resources are needed to provide culturally appropriate facilities for women's participation in schools and communities."

The law or habit of gender segregation often leads to a scarcity of sport facilities for women with the consequence that women are excluded from opportunities to engage in sporting activities and especially competitions. In addition, the scarcity of "sport friendly" environments such as parks and/or the hot climate does not encourage girls and women to be physically active in their leisure time (Al-Sinani \& Benn, 2010). However, when opportunities e.g. for walking or hiking, are available and culturally accepted, the (male and female) population and particularly the middle and upper classes, enjoy active leisure time. The Alborz range, north of Teheran, for example, attracts thousands of "Teheranians" to hike and ski (Pfister, 2003).

\section{MUSLIM WOMEN AND SPORTS - INITIATIVES FOR A CHANGE}

There have been several initiatives to improve the opportunities of Muslim women to participate in sport, and many of these initiatives were originated by both Western and Islamic feminists striving for changes in an Islamic framework. Influential women in Egypt, Iran and other countries used their political connections to lobby for expand opportunities for girls and women to participate in physical activities and sports.
These women, according to Hargreaves, "State feminists", adopt and support the politics of their governments, organise conferences and found national and international associations such as the Arab Women and Sports Association or the Islamic Federation of Women's Sports.

The most spectacular event that placed Muslim sports women on the international agenda are the "Muslim Women's Games" (conducted in 1993, 1997, 2001 and 2005 in Teheran). These games are the initiative of Fa'ezeh Hashemi (daughter of former Iranian President Rafsanjani). At the Muslim Women's Games, the athletes march into the stadium wearing the hijab for the official opening ceremony, watched by a large audience of female and male spectators. The women compete in the various events wearing the usual sports attire but are not exposed to the view of men. The female judges, journalists, doctors and coaches prove that such events can be successfully held without any men in stadiums, gyms or at swimming pools. Delegates from 35 states participated in the Fourth Islamic Women's Games in 2005. The program consisted of 18 events including golf, karate, taekwondo and futsal (indoor five-a-side soccer) as well as table tennis and volleyball for women with disabilities. ${ }^{15}$ The most spectacular event was the opening ceremony. Large groups of ("covered") women - and men - performed a modern dance to psychedelic music, leading the 10,000 spectators to standing ovation (but instigating critique from religious leaders).

The Muslim Women's Games were welcomed in Iran as an opportunity for women's sports and as an alternative to the Olympic Games. Many Iranian participants described the contact and the competition with foreign women as a wonderful experience. However, many athletes (and also many women from the West) pointed out 
that events of this kind would confirm and legitimize the exclusion of women from the "real" world of sports. In addition, athletes complained that the participants from Western countries were not top level athletes and that the events at the Muslim Women's Games were not serious and/or high ranked competitions. A British participant described the different approach by quoting Shirin, one of the players of the successful Iranian team: "'Why is the British team so weak?' Arsenal, Manchester United - don't they have women's teams?" The British player tried to explain that the players representing Britain were there because they were Muslim...that this tournament was special to them as it was the only one in which conditions allowed them to remove their hijab to play. Shirin shrugged. She doesn't wear hijab by choice, like the British girls do. 'I'm ready to play anyone from any religion,' she said. 'I'd like to have good competition" (Steel, 2005). ${ }^{16}$

Another important problem for many athletes is the lack of an audience and media coverage. Women's competitions in Western countries are seldom in the limelight. The lack of interest in women's sports is aggravated by the Islamic law of covering the body, i.e. female athletes can only be shown in photos or on film if wearing the hijab. As a result, women's sports are given little media coverage with negative consequences such as the disinterest of sponsors.

In contrast to the organisers of the Muslim Women's Games, held in Teheran, the Atlanta+ Initiative, launched in the run up to the Olympic Games held in Atlanta (1996), advocated for the participation of Muslim women in the "real" Olympic Games. This initiative by French women asked the International Olympic Committee (IOC) to exclude all NOCs from the Games who do not include women in their delegations (Na- kamura, 2002). The IOC rejected these demands, especially on the grounds that they interfere in the internal affairs of sovereign countries. This decision did not solve the problem and did not end efforts to improve the opportunity for female athletes from Islamic countries to participate in the Olympic Games. The Atlanta-demands are supported by secular feminists and women's rights activists such as Parvin Darabi, born in Iran and currently living in the USA. ${ }^{17}$ Although the IOC never adopted sanctions against NOCs with men only delegations, the Olympic climate has become more women friendly, indicated by the participation rate of women from Islamic countries in the Beijing Games.

These initiatives did not lead to intercultural and interreligious dialogue about Muslim women and sports. The statements of one of the founders of "Atlanta", Linda Weil-Curiel, and the current Head of the Islamic Federation of Women's Sports, Faezeh Hashemi, illustrate ambivalence and the incompatibility of both approaches. Weil-Curiel attacked the IOC because it did not force the NOCs of Islamic countries to send women to the Games:

"I see it as a double betrayal, a betrayal of the spirit of sports and the Olympic Charter,... and I see it as a betrayal of the Muslim athletes who think it normal to participate in international competitions with the normal sports gear ... Why should we admit such a difference which is a clear discrimination. If it is a matter of religion why should Muslim men continue to compete amongst women, wearing shorts, because Islam is the same for men and women, chastity and modesty is also for men so why do men continue to compete?" (Linda Weil-Curiel in BBC in 2005, here quoted in Benn, Pfister \& Jawad, 2010). 
"I think the system that there is only one model in the world for sport, like the OG, is indirectly discriminatory for Muslim women ... the wearing of shorts and tops - Islamic clothing requires different conditions, effects records. They do not say 'don't come here' but in reality I cannot because I want to stay in my hijab and I can't go to that competition because I must do that without hijab" (Faezeh Hashemi in BBC in 2005, here quoted in Benn, Pfister \& Jawad, 2010).

\section{'Accept and respect' - a declaration about Muslim women and sport}

As previously mentioned, there are many reasons for the marginalisation of Muslim women in the world of sport. These include the rigid rules of modern sports on one hand and the interpretation of Islamic laws and restrictions because of cultural traditions on the other. The lack of understanding of the gender discourses and practices in Islamic and Western cultures call for inter-religious dialogues and cross-cultural cooperation.

A workshop in Oman - sponsored by the Sultan Quaboos University and supported by IAPESGW ${ }^{18}$ provided the opportunity for a cross-cultural discussion and an exchange of knowledge, opinions and best practices based on openness, the willingness to learn, and the attempt to understand each other. One man and 15 women (including the author) from 14 countries across Europe, the Middle and Far East, experts on physical education, sport sciences and Islamic studies as well as leading practitioners came together not to 'represent' their countries but as individuals who wanted to share information, ideas and experiences with a cross-cultural perspective. Some women were atheists; many were religious and had different ways of practicing Islam. Some wore Western clothes and hairstyles; others observed the Islamic dress code. ${ }^{19}$

The purpose of the gathering was to identify means to improve opportunities for Muslim women and girls in and through sport and physical education. Due to the widely different backgrounds of the work shop participants, the discussions were very controversial owing to varying perspectives and priorities. Communication and cooperation between individuals and groups with different roots and cultural backgrounds require willingness and the ability to see the world with the eyes of the "others". Waljee (2008, p. 99) strongly criticizes international discourses on gender that use Western models and judge gender relations on the basis of measures such as access, outcomes and performance, enforcing thus evaluations from 'outside' whilst they "... fail to address ... cultural and religious specificity and economic realities of nations in transition or different cultural norms that frame gender relations."

The question remained to what extent it is possible to achieve balance between global values and cultural diversity. In order to avoid this difficult issue, the Oman workshop participants chose to focus on freedom of choice. We did this at the advice of Islamic feminists who shared their considerations about framing empowerment for Muslim women from within the religion. "Islamic feminism has been helpful in showing ways in which space can be created and negotiated for positive change. This knowledge, and the opportunity it created for women's participation in physical activity, was important in understanding the positions of those Muslim women whose most essential layer of identity was religion and for whom, the display of this identity through adherence to modest dress codes 
was integral to sustaining that" (Benn \& Kouskie-Jahromi, 2008). However, choice should also be possible for those women who re-interpret Islam, adapt the rules to modern life and combine their religion with Western attire and elite sports. This is an option in most Islamic countries, as the case of female athletes from Indonesia, Tunis, Morocco, Algeria and Turkey in the 2008 Olympics has demonstrated.

It has to be mentioned that the workshop participants' focus on 'freedom of choice' is not unproblematic because it inherently includes the structure/agency dilemma. In this particular case, one can question whether women (and men) are really free to make decisions about their lives or are their choices determined by their families, environments, culture, and society? It took one exciting week to come to a consensus and to draft the declaration "Accept and Respect" 20 . The declaration supports Islam as an enabling religion that endorses women's participation in physical activity: "1) We affirm the importance of physical education and physical activity in the lives of all girls and boys, men and women. 2) We recommend that people working in the sport and education systems accept and respect the diverse ways in which Muslim women and girls practice their religion and participate in sport and physical activity, for example, choices of activity, dress and gender grouping. 3) We urge international sport federations to show their commitment to inclusion by ensuring that their dress codes for competition embrace Islamic requirements, taking into account the principles of propriety, safety and integrity."

This declaration is directed to Islamic and Western countries as well as to religious and sports leaders encouraging them to accept the choices of women (and men) and to respect their cultural backgrounds. The essence of this decla- ration can be transferred to other areas, groups or cultures. The text is recognized by a number of international sport bodies that lobby for a broad acceptance of the declaration and its principles.

\section{CONCLUDING REMARIS}

This article provided reasons for the marginalization of Muslim women in sports and raised new issues like equality in elite sports. Sports are attractive because they provide equal conditions for competitors, but they compare performances and, focus on differences in order to identify the very best athlete. As such, competitive sports have a limited opportunity to consider diversity and to include "otherness". Sports federations may be amenable to female competitors wearing long trousers but these athletes will not be compensated if they are disadvantaged by their choice of dress. The "Accept and Respect" declaration should have a strong focus on physical education and sports for all; this is where diversity and inclusiveness can be incorporated.

Many issues could not be addressed in the declaration. Gender segregation in sports, i.e. "Women's Games", that relegates women to their "own" events remains a contentious issue. Is participation in these Games satisfying and empowering or do they simply reinforce marginalization of women's sports? This question arises also for other population groups and events, for example, homosexual people and the "Out Games".

The Western rooted 'sports for all' movement may also pose problems. The issue is whether Western "body politics" that emphasize youth, slimness and fitness for women, can and should be integrated into the lifestyle of women from Islamic countries. 


\section{REFERENCES}

Al-Sinani, Y. \& Benn, T. (2010). The Sultanate of Oman and the position of Omani girls and women in the field of physical education and sporting activity. In T. Benn, G. Pfister, \& H. Jawad (eds.), Muslim women and sport. London: Routledge. In print.

Alsharif, A. (2008). Ladies at the Forefront. Egypt Today, July.

Bannayan, A. (2008). Muslim Sportswomen Gain Standing in Beijing. Womens eNews. http://www. womensenews.org/story/athleticssports/080807/ muslim-sportswomen-gain-standing-beijing (2008-08-07).

Benn, T. \& Kouskie-Jahromi, M. (2008, August). Evidence and Influence, making a difference for girls and women in physical education and sport. Paper presented at the IAPESGW Symposium during the International Convention on Science, Education and Medicine in Sport. Guangzhou.

Benn, T., Pfister, G. \& Jawad, H. (eds.) (2010), Muslim women and sport. London: Routlegde. In print.

El Houda Karfoul, N. (2010). Women and Sport in Syria. In T. Benn, G. Pfister, \& H. Jawad (eds.), Muslim women and sport. London: Routlegde. In print.

Daiman, S. (1995). Women in Sport in Islam. In ICHPER-SD Journal, 32(1). 18-21.

Delaney, C. (1991). The Seed and the Soil. Gender and Cosmology in Turkish Village Society. Berkeley/Los Angeles/Oxford: University of California Press.
Hargreaves, J. (1997). Sporting females. Critical issues in the history and sociology of women's sports. London: Routledge.

Hargreaves, J. (2007). Sport, exercise, and the female Muslim body: negotiating Islam, politics and male power. In J. Hargreaves \& P. Vertinsky (eds.), Physical culture, power, and the body. London: Routledge, 74-101.

Khader, N. (2006). AEre og skam. København: Borgen.

Koca, C. \& Hacısoftaoglu, I. (2010). Sport participation of women and girls in modern Turkey. In T. Benn, G. Pfister, \& H. Jawad (eds.), Muslim women and sport. London: Routledge. In print.

Kouskie-Jahromi, M. (2010). Physical activities and sport for Iranian girls and women. In $\mathrm{T}$. Benn, G. Pfister, \& H. Jawad (eds.), Muslim women and sport. London: Routledge. In print.

Kremers, S. et al. (2010). Palestinian Women's National Football Team Aims High. In T. Benn, G. Pfister, \& H. Jawad (eds.), Muslim women and sport. London: Routlegde. In print.

Nakamura, Y. (2002). Beyond the hijab: female Muslims and physical activity. Women in Sport \& Physical Activity Journal, (11). 21-48.

Pfister, G. (1997). Frauen und Sport in der Türkei. In M. Klein \& J. Kothy (eds.), Ethnisch-kulturelle Konflikte im Sport. (127-145). Hamburg: Czwalina Verlag.

Pfister, G. (2003). Women and Sport in the Iran: Keeping Goal in the Hijab. In I. Hartmann- Tews \& G. Pfister (eds.), Sport and Women. Social Is- 
sues in International Perspective. (207-223). London: Routledge.

Schiffauer, W. (1983). Die Gewalt der Ehre. Frankfurt: Suhrkamp.

Schirrmacher, C. \& Spuler-Stegemann U. (2006). Frauen und die Scharia. München: Goldmann.

Sfeir, L. (1985). The Status of Muslim Women in Sport: Conflict between Cultural Tradition and Modernization. International Review for the Sociology of Sport, 20(4), 283-306.

Steel, J. (2005). Sport and the scarf. BBC NEWS, 9. December 2005.

http://news.bbc.co.uk/2/hi/middle_east/4511680. stm

Waljee, A. (2008) Researching transitions: gendered education, marketisation and Islam in Tajikistan. In S. Fennell, \& M. Arnot (Eds) Gender Education and Equality in a Global Context, London Routledge, 87-101.

Wirdati, M. R. (2006). Muslim Women and Sports in the Malay World: The Crossroads of Modernity and Faith. Chiang Mai: Silkworm books.

\section{NOTES}

1. The Olympic Charter: http://en.beijing2008.cn/spirit/symbols/charter/index.shtml

2. This article deals with women from Islamic countries (see footnote 6). Muslim refers here to the home country and culture of the women and does not indicate religion or religiosity.

3. 1900 and 1904 the Games were conducted as part of a World Fair, and there was not a clear definition which events were Olympic and which not. Therefore 1908 was chosen as point of departure.

4. See the webpage of the Beijing Olympics: http:// en.beijing2008.cn/
5. The definition of the term sport varies widely depending on language and culture. In a broad sense, sport means "sport for all" and includes a variety of physical activities. "Modern" sport with a focus on quantitative performances, competition and record orientation emerged in the 19th century.

6. Included are countries with more than $70 \%$ Muslims among the population in Asia and North Africa. The states of the former USSR are not taken into consideration. For the numbers of male and female athletes at the Games of 2008, see http://en.beijing2008.cn/.

7. http://www.metu.edu.tr/ settar/hp4.htm; see also Sfei (1985) with data about elite sport of Muslim until 1984

8. See also http://www.egypttoday.com/article.aspx?Article $\mathrm{ID}=8092$

9. See the Overall Medal Standings: http://results.beijing2008.cn/WRM/ENG/INF/GL/95A/GL0000000.shtml.

10. See also many web sites, among them http://muslimahmediawatch.org/2008/08/14/muslimahs-at-the-beijing-olympics/

11. www.tuik.gov.tr.

12. On women's sport in Islam, see K. Lindsay K et al. (1987) Islamic Principles and Physical Education. Unicorn, 13(2), 75-78; Sfeir (1985); S. Yaldai (1988). Frauensport im Islam. In P. Jakobi \& H.-E. Rösch (eds.), Frauen und Mädchen im Sport. (121-134). Mainz: Matthias-Grünewald-Verl.; Dai man (1995); K. Walseth \& K. Fasting (1999, June). Islam Women and Sport. Paper presented at the Women's Worlds 99. 7th International Interdisciplinary Congress on Women, Tromsøe. Further readings P. de Knop et al. (1996). Implications of Iran on Muslim girl's sport participation in Western Europe. Sport, Education and Society, 1(2). 147-164.; K. Walseth (2006). Young Muslim women and sport: the impact of identity work. Leisure Studies, 25(1). 75-94.; D. Dahl (2007). Zum Verständnis von Körper, Bewegung und Sport in Christentum, Islam und Buddhismus - Impulse zum interreligiösen Ethikdiskurs im Spitzensport. Berlin: Logos Verlag.

13. Times Online. 10. July 2008, http://www.timesonline.co.uk/ tol/sport/more sport/article4304884.ece

14. See for the literature about the veil Hargreaves (2007).

15. http://www.mwlusa.org/news/iran_women's_games.htm

16. See also http://www.taipeitimes.com/News/editorials/archives/2005/09/27/2003273432

17 http://www.homa.org/

18. International Association of Physical Education and Sport for Girls and Women.

19. The participants came from Bahrain, Bosnia and Herzegovina, Denmark, Egypt, Iran, Iraq, Malaysia, Morocco, Oman, South Africa, Syria, Turkey, the United Arab Emirates and the United Kingdom.

20. See the declaration in the webpage of IAPESGW http:// www.vagacms.co.uk/vagacms/iapesgw/ianews.aspx 